\title{
Using Genetic Research to Inform Imperiled and Invasive Species Management
}

The long-term viability of species and populations is related to their potential to migrate, reproduce, and adapt to environmental changes. In the southeast United States, U.S. Geological Survey (USGS) scientists are providing resource managers with genetic information to improve the long-term survival and sustainability of the Nation's aquatic species. Research focused on native and imperiled species can assess the genetic factors influencing their survival and recovery, while work on invasive species can provide information on their proliferation, dispersal, and impacts on native species.

\section{Imperiled Native Species}

Genetic diversity plays a critical role in the ability of a species to survive. A diverse gene pool can increase a population's ability to adapt to diseases, habitat modifications, or changes in the environment, such as altered hydrology and hurricanes. Small, imperiled populations typically have reduced genetic diversity, which can increase susceptibility to disease, decrease population viability and negatively influence fitness, or the number of surviving offspring.

Quantifying the genetic diversity of a species or population is a useful first step in understanding the factors affecting imperiled species. Using nuclear DNA (deoxyribonucleic acid), scientists can identify inbred populations before physical defects are present. This type of genetic information can help managers identify whether additional conservation measures are warranted. Genetic diversity data combined with morphological data can be used to assist with taxonomic classifications, especially for species that are at risk of extinction and are undergoing conservation listing decisions, or with samples where the species is not clearly identifiable morphologically, such as in poaching cases. Another type of analysis, known as phylogenetics, can determine the evolutionary relatedness of populations, specifically useful for assisting with decisions regarding the conservation status and management of imperiled species. Similarly, geneticists can use phylogeography to address the historic processes that resulted in the geographic distribution of organisms, while landscape genetics addresses the influence of ecology and current environmental features (rivers, mountains, roads, etc.) on genetic connectivity at a finer scale.

Knowledge of population patterns across the landscape can help improve imperiled species management. For example, if populations that were once connected are now isolated or have extremely low diversity, managers may use conservation measures, such as habitat corridors, to reconnect populations and improve the viability of the species.

Genetic tools can also identify individual animals, their sex, and pedigree or familial relationships, which can provide life history information. Repeated identification of individuals over time, known as mark-recapture studies, can help with determining population sizes, trends, and survival rate estimates. This complementary approach to traditional inventory and monitoring methods can improve the time and cost effectiveness of assessing population status and trends.

\section{Invasive Species}

Genetic tools can also be used to rapidly identify, monitor, and manage non-native species. Invasive and exotic species can potentially harm native populations, disrupt natural ecosystems, and transmit nonindigenous diseases to human and native wildlife populations.

USGS geneticists are using molecular markers to confirm the identity of invasive species and to determine the source populations for these species.

By assessing these origins of non-native species, scientists can help managers learn more about how they may have been introduced into the environment, through intentional releases or

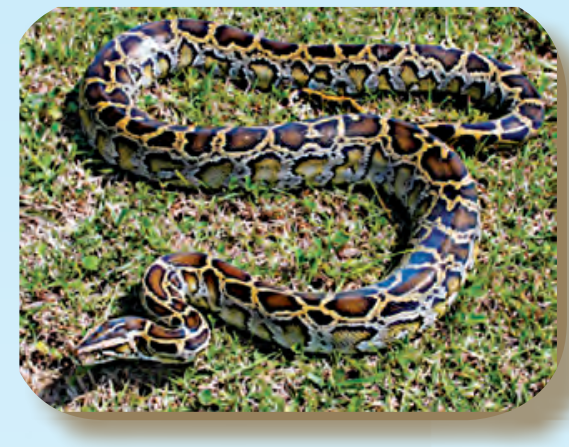

Invasive Burmese python in Everglades National Park. National Park Service photo.

unintentional escapes, and gauge the likelihood of the population increasing and becoming established in the ecosystem. Genetic examination of gut contents can determine the native species that are preyed upon by invasive species, which helps managers assess the impact of invasives on the environment and imperiled species.

An improved understanding of genetic population dynamics can also be used to determine whether separate populations of non-native species exist in the wild. This determination can help managers target the main breeding population of invasive species for control or removal efforts.

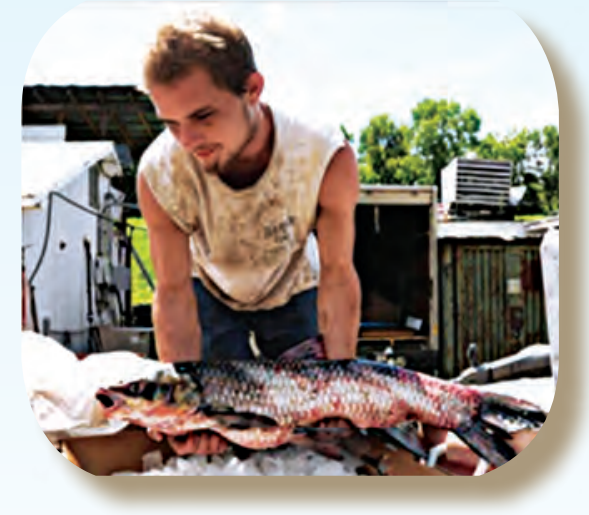

Young wild-caught black carp taken by commercial fishers in the Red-Atchafalaya River system. Photo by Dr. Leo G. Nico, USGS. 


\section{The "First Generation" of Conservation Genetics}

Genetic studies have traditionally focused on developing DNA markers, because they are useful for phylogenetics, phylogeography, species identification (through DNA barcoding), and other types of conservation genetics research.

Molecular markers, typically mitochondrial or nuclear microsatellites, can be used to understand ancestral relationships on a long-term, geologic time scale, which is useful for making inferences about the types of conditions that a species was adapted to in the past. They can also help managers understand more recent breeding patterns among different populations and how those patterns influence the movement and mixing of individuals across waterways or other types of corridors, such as ocean migration routes.

\section{Research on Imperiled West Indian Manatee Populations}

Extensive USGS studies of the West Indian manatee provide an example of the various types of management-oriented questions that can be addressed through genetic research. The Florida manatee is an endangered marine mammal found in the coastal waters of Florida and is one of two subspecies of the West Indian manatee. Little systematic information was previously available to determine the genetic connectivity among various populations of the Florida manatee or whether they bred with the other West Indian subspecies, the Antillean manatee. USGS molecular research has helped species managers understand the following issues:

- Coastal Concerns - Conservation genetic studies in the Florida manatee have found little population sub-structuring and low overall nuclear genetic diversity. This has helped the U.S. Fish and Wildlife Service better evaluate management approaches. Additionally, pedigree studies can be used to determine family units and the number of successfully breeding males in the population.

- Caribbean Cousins-USGS geneticists surveyed microsatellite markers to help determine the genetic relationships between the Antillean Puerto Rico manatee and Florida manatee for the first time - a major question, given that both populations are currently listed and managed together under the U.S. Endangered Species Act.

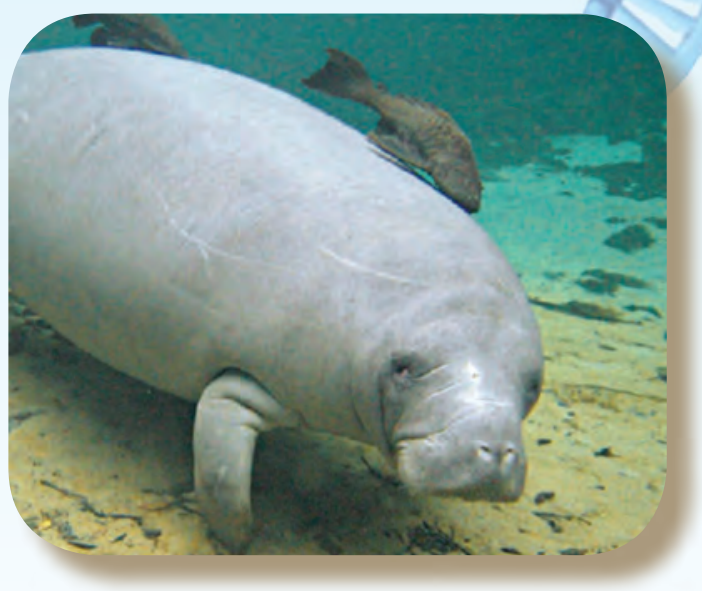

USGS is using genetic techniques on both the Florida manatee and invasive armored catfish. Photo by James Reid, USGS.

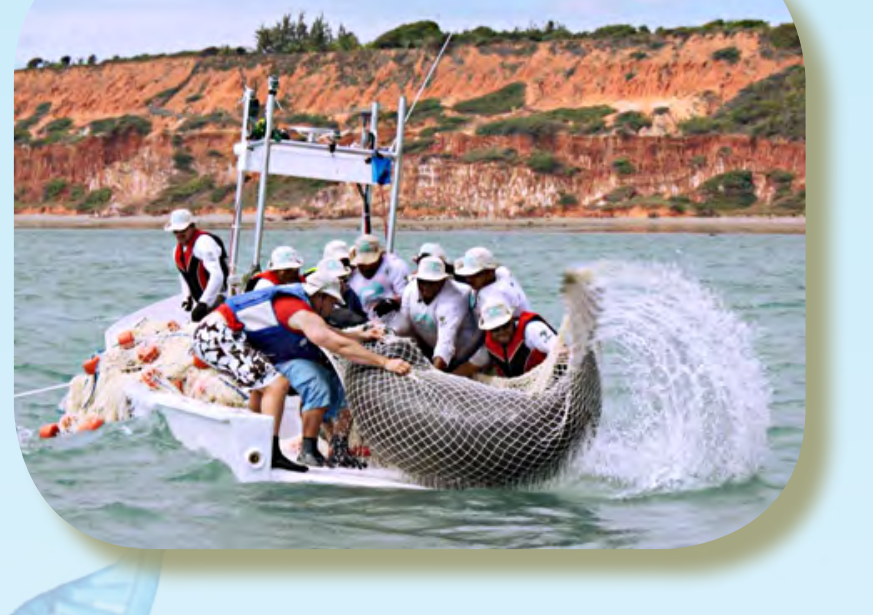

Manatees are netted and brought into a boat for health assessments and tracking studies in Brazil. Photo by Michael Lusk, U.S. Fish and Wildlife Service.

- Trending Techniques-Understanding trends in survival is crucial for estimating overall mortality and recruitment rates in manatee populations. A new Florida manatee modeling approach based on mark-recapture methods is being designed to jointly analyze photo-identification and genetic data. Unlike visually-based documentation, genetic data does not require marks on a manatee's body to follow its life history. For the first time, unscarred individuals, unaffected by encounters with boats, can be factored into the analysis of population trends. This will lead to more encompassing survival estimates and better assessment of the population size and extinction risk.

- Recovery and Release-Brazil is home to approximately 500 manatees that belong to the Antillean subspecies and are classified as critically endangered. Marine mammal managers in that country have begun rehabilitation programs, similar to those in Florida, for injured manatees and calves that have been found stranded alive. USGS studies are using mitochondrial and microsatellite markers to understand their phylogeography. The results will allow managers making recovery plans to take into account genetic relatedness and determine how to strategically release rehabilitated individuals in a way that supports ongoing genetic mixing, diversity, and fitness. 


\section{Genetic Research on Invasive Species}

Genetic research provides molecular tools that can be used to rapidly identify and monitor non-native species and make informed decisions about invasive species control and management. USGS geneticists are using molecular markers to distinguish genetic differences among groups of non-native species existing in the wild, in order to determine whether there are distinct populations. This can be crucial if there is one main breeding population (a source population) that is dispersing to other areas. Managers seeking to control or remove invasive species can use this information to focus their efforts on source populations. The same tools that provide information about the origin of non-native species may also be useful for determining whether these species were brought into the environment intentionally through known channels, or were unintentionally released or escaped from captivity.

Carp Conundrum - The black carp is a large ( $>1$ meter long) riverine fish, the most recent of the four Asian carps to be introduced and become established in U.S. open waters. In their native range black carp feed heavily on mussels and snails, and are therefore considered a threat to North America's imperiled native mollusks. The species has been used in aquaculture for more than two decades and wild populations likely originated as escapes or releases from aquaculture facilities. Genetic analyses will compare black carp from both wild and captive populations to assess black carp population structure, relatedness, and genetic diversity. These results may provide information on introduction pathways and subsequent dispersal patterns of wild black carp populations in the Mississippi River Basin.

Lionfish Larvae - To support managers working to protect the habitat of native reef fishes, mitochondrial markers are providing information to track the genetic relatedness of lionfish throughout the Caribbean. This information can be used to help determine the source populations of larvae.

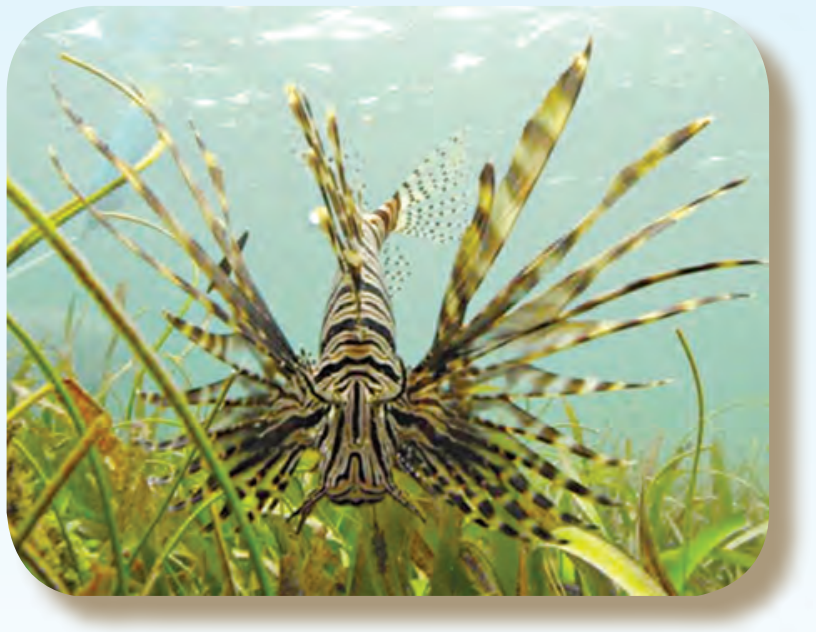

Invasive lionfish in Puerto Rico.

Photo by Antonio Mignucci-Giannoni, Inter American University of Puerto Rico.
Asian tiger shrimp - Recently, there has been a 10 fold increase in reports of this non-native shrimp in coastal waters from North Carolina to Texas. The shrimp can grow up to one foot in length and its potential for negatively impacting native ecosystems is currently being studied. In the meantime, the source of these shrimp is uncertain, and no one knows the specific pathways or number of initial introduction events leading to their presence in U.S. waters. It is also unclear whether the increase in numbers throughout the region is due to local breeding, dispersal by ocean currents, or other mechanisms. Molecular studies are helping to understand the introduction pathways and genetic relatedness of individuals found throughout the southeast U.S. to begin piecing together the source of the invasion and to better understand the non-native range expansion.

\section{Python Parameters-The} invasive and exotic Burmese python is established and breeding in Everglades National Park and has the potential to occupy the entire greater Everglades region. Pythons may adversely affect populations of native and endangered species. Genetic information can aid resource managers in monitoring the invasion of this non-native species. Therefore, USGS scientists developed a suite of new python microsatellite markers using next-generation sequencing techniques. These markers make it easier for

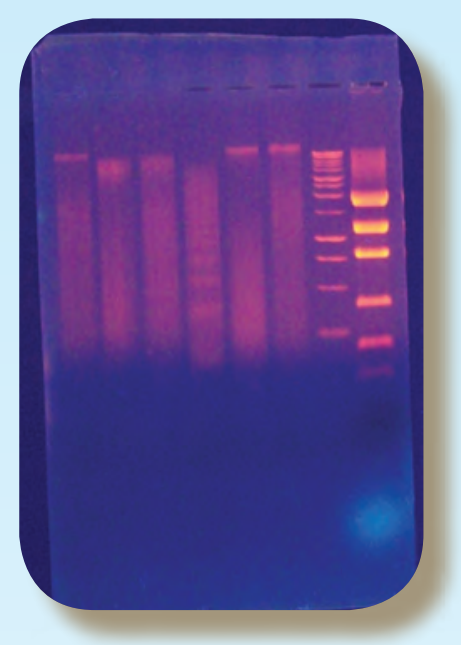

Gel electrophoresis visualizing python genomic DNA. Photo by Margaret E. Hunter, USGS. researchers to identify their genetic diversity, growing or declining population sizes, and breeding patterns over geographic areas. Additionally, there are plans to analyze the DNA of python gut contents to identify which species pythons feed upon in the wild.

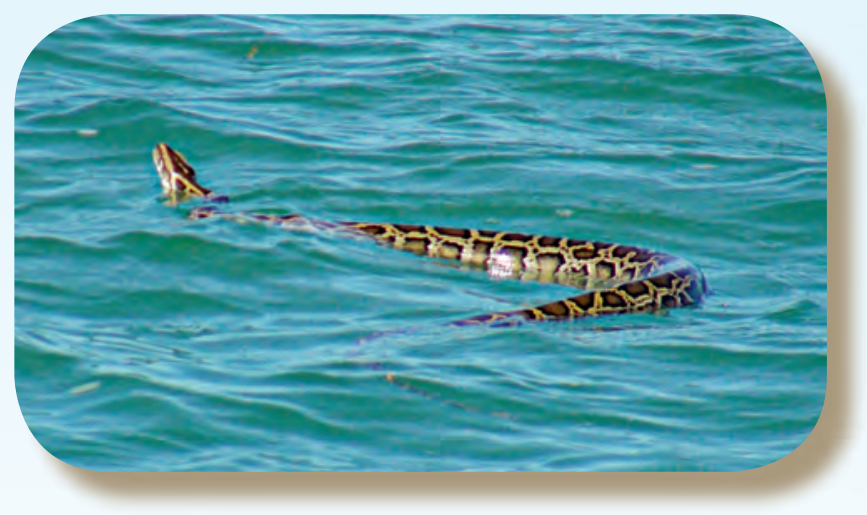

Burmese python swimming in Florida Bay from the end of Twisty Channel toward End Key on November 16, 2011. Photo by Camp Walker, Catalyst Charters, Islamorada, Florida. 


\section{What is eDNA?}

Environmental DNA (eDNA) is a term used to describe genetic material found in the environment. It comes from biological samples such as cells, microorganisms, tissue, and feces, and can originate from both living and dead organisms. Researchers identify it by sampling water, sediment, soil, or even air. In the lab, the small quantities of eDNA are extracted from the environmental sample and copied exponentially until there is enough material for genetic sequencing and species determination.

Environmental DNA techniques can use molecular markers to target a particular species. For example, aquatic eDNA surveillance is useful to identify specific invasive species, particularly those that are difficult to detect because they are concealed or present in small numbers. However, other techniques, including metagenetics and metagenomics, can be used to sequence all the organisms or genetic material present in an environmental sample. A researcher might sequence all the microorganisms found in a soil sample to better understand soil productivity.

USGS geneticists are developing species-specific eDNA markers that will make it possible to monitor invasive armored catfish. Water samples collected from rivers, lakes, and springs can be analyzed for residual eDNA to detect the presence of invasive catfish. Further, eDNA can also be used to track their dispersal to new areas and assist in targeting specific waterways for more intense monitoring

\section{Next-Generation Genetic Sequencing: Why it is Revolutionizing Conservation Genetics}

Next-generation sequencing allows scientists to explore questions that were once limited by the time-consuming process of decoding individual genetic sequences. A rapidly evolving set of technologies now allows for automated gene sequencing, enabling geneticists to produce thousands or millions of sequences in parallel. This makes it possible to sequence an organism's full genome more easily or analyze functional DNA, genes that code for proteins (the building blocks of our bodies). These genes are turned on at different times and at varying levels in response to developmental or environmental cues. This more comprehensive and easily obtainable sequence information allows geneticists to more readily develop molecular tools or compare differences in individual genome sequences. Additionally, changes in expressed genes can be used to assess a species' ability to adapt to disease or environmental challenges, such as climate change.

Perspective on Pythons - The microsatellite markers that are being used to analyze Burmese python population structure in the Everglades were developed using next-generation sequencing. Previous studies found little genetic diversity and a lack of differentiation among pythons from different geographic areas in the Everglades. Therefore, the additional nuclear microsatellite markers can provide a finer-scale resolution of genetic differences and enabled comparison of genetic diversity of pythons within and outside Everglades National Park. With the aid of genetic tools, managers may be able to locate breeding sources and prioritize areas for removal efforts.

Manatee Adaptation - Using new techniques, USGS geneticists launched an innovative project to find functional markers that vary according to a manatee's physiological and immune state and can provide clues to how manatees adapt to changing environmental conditions. This is done through sequencing the ribonucleic acid (RNA; copied from DNA) of genes that are currently in use. The suite of RNA from these actively expressed genes is called the transcriptome. Sequencing of RNA can also be used to determine the health of individual manatees and how they respond to disease and environmental stressors.

Coral Diagnostics - Coral disease in the Caribbean has long puzzled scientists. In the U.S. Virgin Islands, next generation sequencing will provide crucial pieces to the puzzle by generating a large set of gene sequence transcripts. Scientists can then compare coral, microorganisms, and symbionts inhabiting healthy as well as diseased corals.

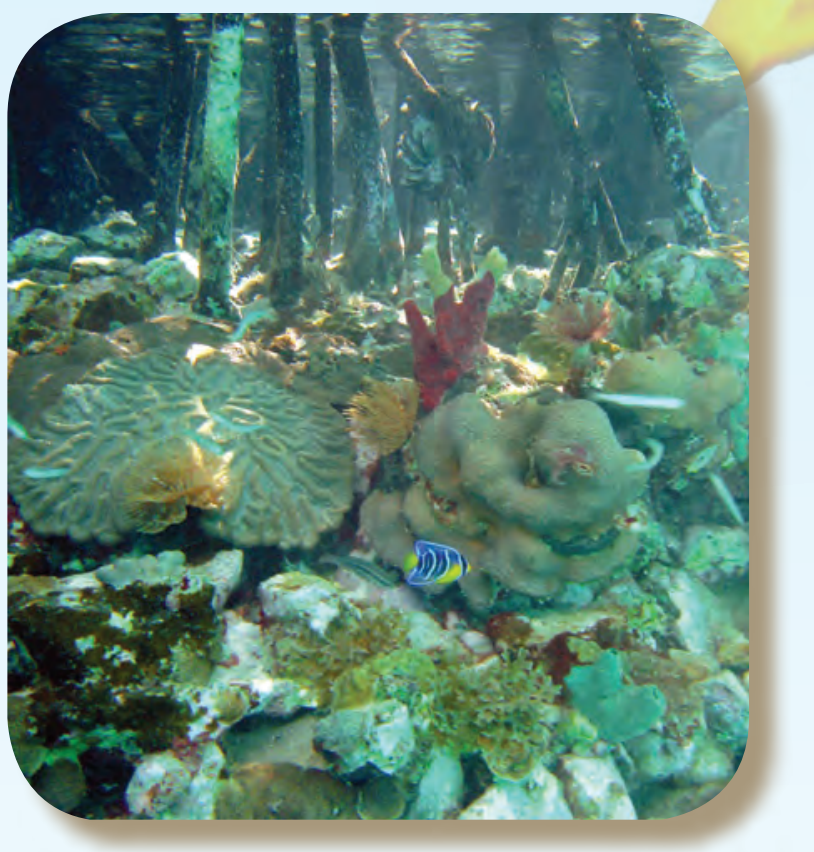

Corals in the U.S. Virgin Islands. Photo by Caroline Rogers, USGS.

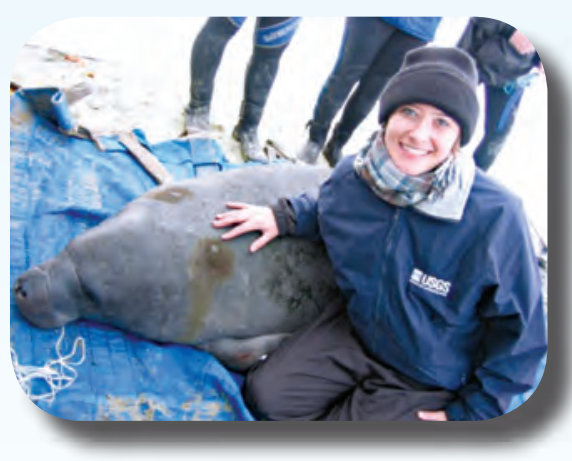

Manatees are brought ashore for health assessments and tracking studies. Photo by Heather Daniel, University of Florida.
For More Information

Dr. Margaret E. Hunter,

Research Geneticist

USGS Southeast

Ecological Science Center 7920 NW 71st Street

Gainesville, Florida 32653 Phone: (352) 264-3484, Email:mhunter@usgs.gov http://fl.biology.usgs.gov/ genetics/index.html

DNA clipart used with permission made available from $h t t p: / / w w w$. all-about-forensic-science.com. 